\title{
An Examination of Sex Differences in Social Support Among Older Men and Women ${ }^{1}$
}

\author{
Toni C. Antonucci ${ }^{2}$ and Hiroko Akiyama
}

The University of Michigan

This paper is designed to empirically investigate sex differences in social support. Several types of sex differences are examined, including quantity and quality of support, the relationship between quantitative and qualitative measures of support, the number and source of support provided and received, and the relative predictive power of quality and quantity of support on well-being. The data are taken from the Supports of the Elderly, a national survey of older people (Kahn and Antonucci, 1984). Included in the present study are 214 men and 166 women ranging in age from 50 to 95 who are married and have at least one child. The analyses reveal that women have larger networks and receive supports from multiple sources, while men tend to rely on their spouses exclusively. Men report greater satisfaction with marriage than women. Quantitative supports are more related to qualitative supports for women than for men. For both sexes, the quality of support rather than the quantity of support has significantly greater effects on well-being; both the quantity and quality of social support have a greater impact on the well-being of women compared to men.

\footnotetext{
'Preparation of this paper was supported in part by Grant \#AG01632 and by a Research Career Development Award to the senior author (\#AG00271) from the National Institutes on Aging. Dr. Akiyama was supported by AG00117, a Research Training Grant from the National Institutes on Aging. The authors would like to express their thanks to Sue Meyer for help in the preparation of this manuscript; to Halimah Hassan for assistance with data analyses; and to Anita DeLongis for comments on earlier drafts of this manuscript.

The data computation upon which this paper is based employed the OSIRIS IV computer software package, which was developed by the Institute for Social Research, The University of Michigan, using funds from the Survey Research Center, Inter-University Consortium for Political Research, National Science Foundation, and other sources.

${ }^{2}$ To whom reprint requests should be addressed at Institute for Social Research, The University of Michigan, P.O. Box 1248, Ann Arbor, MI 48106.
} 
Many researchers have noted that the nature of interpersonal relationships seems different for men and women (Maccoby \& Jacklin, 1974; Troll, 1986). This difference apparently extends to the structure and function of support networks. Although few past researchers have focused on sex differences in social support specifically (see Vaux, 1985), several early studies examining interpersonal and social relationships more generally have documented what appear to be substantial differences in the quantitative supports of men and women. In general, it has been found that the structure of the support network differs for men and women. Women appear to have larger, more multifaceted, networks - that is, a larger variety of people are in their network and each of these people serve several functions. In contrast, the network structure of men appears considerably more limited, consisting predominantly of a single person, the wife, who performs most support functions for them.

In a series of large-scale surveys, women have consistently been shown to have larger networks than men (Babchuk, 1978-1979; Harris, 1975; Longino \& Lipman, 1982; Campbell, 1980; Veroff, Douvan, \& Kulka, 1981). In a parallel finding, Levitt, Antonucci, Clark, Rotton, \& Finley (1985) reported that, among a sample of elderly with relatively impoverished networks, males were particularly likely to be isolates and in poorer health.

Studies of college students also generally show women to have a support advantage. For example, Burda, Vaux, and Schill (1984) examined social support resources of young college men and women. Their data were consistent in indicating that women had greater support resources than men. One advantage of this study was the use of multiple measures of support resources including network characteristics, availability of several modes of support, and perceived supportiveness of family and friends.

In addition to the sex differences in support structure, there is some evidence that networks serve different functions for men and women. Lowenthal and Haven (1968), in a now classic sociological study, reported notable sex differences in support function of older individuals. They found that women were more likely than men to report a confidant relationship and that, whereas men were most likely to mention their wives as confidants, wives were not equally likely to mention their husbands as confidants. Leavy (1983) concluded that women generally report more sources of support and benefitting more from these supports than men. Butler, Giordano, and Neren (1985), using a sample of graduate students, found that, compared to men, women reported both asking for and receiving more support during personal stress events than men.

Studies have also examined the sex differences in the relative effects of social support on psychological distress and/or well-being. Sarason, Levine, Basham, and Sarason (1983), for example, found that, for college men, 
number of social supports was related (negatively) to depressive complaints. But for college women, number of and satisfaction with social support providers was related (negatively) to anxiety, depressive, and hostility symptoms. It should also be noted, however, that Kesseler, McLeod, and Wethington (1985) suggest that the costs of supportive relationships may be higher for women than for men in that women report higher levels of psychological distress when members of their network are exposed to stress.

Although the findings reviewed thus far suggest a fair degree of consistency in indicating that women have larger, more multifaceted, support networks, there have been occasional but persistent findings indicating what seems to be a reverse in or lack of sex differences in supportive relationships. For example, Depner and Ingersoll-Dayton (1985) examined spousal support using a sample of married people 50 years of age and over. They found that women report both receiving and providing less support to their spouse than men report. Babchuk (1978-1979) found no differences in the number of primary relations reported by men and women, but there were differences in the number of confidant relatives reported by men and women. Griffith (1985) found that there were no significant relationships between respondent gender and network characteristics, nor were there significant differences in the relationship between network characteristics and mental health for men and women. These inconsistencies among research findings may reflect differences in the definition of social support. For example, Griffith asked about "people whom you can depend on" rather than about affective relationships.

More importantly, the explanation for these differences seems to lie in the fact that, as Troll (1986) and others have suggested, the nature of social ties are different for men and women. It may be helpful to clarify the presence and extent of differences in the support relationships. In general, previous studies have focused on only one aspect of sex differences in social support using relatively select samples (Vaux, 1985). Some studies have highlighted quantitative differences in the network, e.g., size, number of children/friends, and number of supports received/provided. A few studies have focused on more qualitative dimensions of social support, that is how individuals feel about their support network or the support they receive/provide. Still other studies have focused on the relationship between quantitative measures of support and well-being. None of the studies reviewed have examined qualitative measures of support, or the relationship between qualitative support and well-being in any significant detail. Few studies currently in the literature examine the relative influence of quantitative and qualitative support on well-being. Thus, previous studies may have been unable to clarify the sex differences in social support because they have been limited by the representativeness of the sample, the number or types of support meas- 
ures available, and by a focus on either quantitative or qualitative measures of social support.

The purpose of the present study is threefold: to examine sex differences in and the relationship between quantitative and qualitative measures of social support within the same study, to examine sex differences in the source and target of different types of support, and to examine the relative influence of these qualitative and quantitative measures of social support on well-being. By capitalizing on a unique data set containing in-depth social support measures from a national sample of middle-aged and older adults, it should be possible to clarify the apparent inconsistencies in the support literature. While the present paper focuses on sex differences in this sample, midand late-life age differences have also been explored in one of our reports elsewhere (Antonucci \& Akiyama, 1987).

\section{METHOD}

\section{Sample}

The data are taken from the Social Networks in Adult Life survey, which was conducted by the Survey Research Center at The University of Michigan in 1980 (Kahn \& Antonucci, 1984). Respondents were randomly selected within a multistage sample of households and consisted of 718 men and women ranging in age from 50 to 95 . The response rate was $73 \%$. Trained interviewers conducted in-home, structured interviews, which were approximately one hour in duration. The analyses presented in this paper are based on the 214 men and 166 women who were married and had at least one living child.

\section{Measures}

Respondents were asked to list people who are close and important to them on a personal network diagram consisting of a set of three concentric circles with a smaller circle in the center in which the word you was written. Respondents were then asked a series of question concerning the quantity and quality of support (i.e., confiding, reassurance, respect, care when ill, talk when upset, and talk about health) received from and provided to their network, and the overall well-being of the respondents themselves. The measures employed in the analyses to follow are eight measures of quantity of support, seven measures of quality of support, and one measure of well-being.

The quantity support measures include network size, whether or not spouse is included in network, the number of children in network, the num- 
ber of friends in network, frequency of contacts, the total number of people from whom the respondents received six kinds of support, the total number of people to whom the respondents provided six kinds of support, and reciprocity which was computed by subtracting the number of supports provided from the number of supports received. The quality measures are satisfaction with marriage, satisfaction with family, satisfaction with friends, the extent to which respondents feel misunderstood by network, the extent to which the network gets on the respondent's nerves, the extent to which respondents experience their networks as too demanding, and whether or not respondents want more people on whom they could depend. Well-being was measured by a 5 -point happiness scale.

\section{RESULTS}

This section is organized as follows: Sex differences in quantitative and qualitative measures of social support are presented first. This is followed by an examination of the relative predictive power of quantitative measures for qualitative measures of social support. Next, sex differences in the exchange of different types and different sources of support are examined. Finally, the relative influence of quantitative and qualitative measures of social support on happiness are considered in separate regression analyses for men and women.

Table I provides the mean scores for men and women, and $t$-test results of the eight quantity support measures and seven quality support measures. With respect to the overall quantity support measures, the $t$-test results indicate two significant sex differences. Compared to men, women report significantly larger support networks $[t(374)=-2.52, p<.05]$ and that they receive a greater number of supports than men $[t(363)=-2.00, p<.05]$. The findings for overall differences in qualitative support indicate only one significant sex difference. Men report that they are more satisfied with their marriage than women $[t(366)=3.81, p<.05]$. It is interesting to note that, in a parallel logit regression analysis on sex differences in quality measures, which is not presented in the table, significant sex differences in friendship satisfaction also emerged. The logit analysis indicates that, compared to men, women are more satisfied with friends. There were no other differences between the two analyses.

The relationship between the set of eight quantity measures and the set of seven quality measures are examined by a canonical correlation analysis for men and women separately. The largest canonical correlations between the two sets of measures of support are .31 and .44 for men and women, respectively. These differences are impressive since they indicate that the total variance in the specified combination of quality measures accounted for 
by quantity measures is twice as large among women $(20 \%)$ as men $(9 \%)$. Further, the magnitude of canonical coefficients for the quantity measures indicates that having a spouse in one's network has the greatest influence on the quality of support among men, whereas reciprocity (over providing) has the greatest effect among women.

Four categories of sources of support (spouse, children, friends and total network) are presented in Table II. As the last two columns indicate, most men and women in our sample report receiving all six kinds of support from at least one member of their support network. The percentages range from $99 \%$ of men and women receiving sick care to $80 \%$ of men and $76 \%$ of women who report that they talk to someone about their health. It is noteworthy that $20 \%$ of the men and $24 \%$ of the women do not talk about their health with anyone. There is only one statistically significant sex difference in the proportion of those who report receiving support from overall network. Women are more likely to report that they confide in others than men.

Table 1. Sex Difference in Social Support

\begin{tabular}{|c|c|c|c|c|c|}
\hline & \multicolumn{2}{|c|}{ Means } & \multirow[b]{2}{*}{ T-test $t$} & \multicolumn{2}{|c|}{$\begin{array}{l}\text { Regression an- } \\
\text { alysis on happi- } \\
\text { ness and social } \\
\text { support }\end{array}$} \\
\hline & Male $(n=214)$ & Female $(n=166)$ & & Male & Female \\
\hline \multicolumn{6}{|l|}{ Quantity of social support } \\
\hline Network size & 8.62 & 9.90 & $-2.52^{\alpha}$ & .01 & -.10 \\
\hline Proportion of spouse & .96 & .93 & 1.02 & .03 & -.09 \\
\hline $\begin{array}{l}\text { Number of children } \\
\text { in network }\end{array}$ & 2.63 & 2.69 & -.34 & .05 & -.02 \\
\hline $\begin{array}{l}\text { Number of friends in } \\
\text { network }\end{array}$ & 1.05 & 1.00 & .28 & -.04 & .07 \\
\hline Frequency of contact & 3.74 & 3.78 & -.77 & .03 & .01 \\
\hline $\begin{array}{l}\text { Number of supports } \\
\text { received }\end{array}$ & 16.98 & 19.08 & $-2.00^{a}$ & .00 & .13 \\
\hline $\begin{array}{l}\text { Number of supports } \\
\text { provided }\end{array}$ & 23.26 & 25.83 & -1.83 & & \\
\hline Reciprocity & -.96 & -1.08 & .74 & $-.19^{b}$ & $-.20^{\circ}$ \\
\hline Satisfaction with marriage & 6.67 & 6.24 & $3.81^{b}$ & .12 & $.21^{a}$ \\
\hline Satisfaction with family & 6.07 & 5.90 & 1.08 & .06 & .16 \\
\hline Satisfaction with friends & 6.17 & 6.39 & -1.86 & $.20^{b}$ & .01 \\
\hline Network too demanding & 2.39 & 2.54 & -.99 & -.09 & -.01 \\
\hline Network get on nerves & 1.80 & 1.73 & .54 & -.08 & $-.18^{a}$ \\
\hline $\begin{array}{l}\text { Network do not } \\
\text { understand }\end{array}$ & 2.32 & 2.12 & 1.24 & .00 & .05 \\
\hline Want more network & 2.36 & 2.37 & -.01 & $-.15^{a}$ & -.07 \\
\hline$F_{2}$ & & & & $3.03^{a}$ & $3.17^{b}$ \\
\hline$R$ & & & & .18 & .23 \\
\hline
\end{tabular}




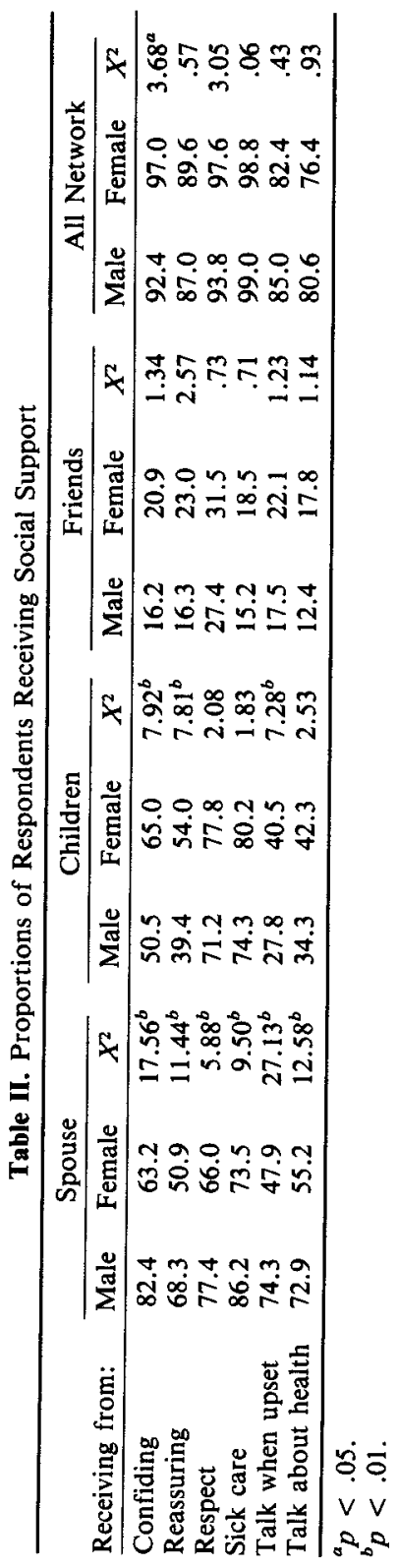


The sources of support, however, are strikingly different between men and women. Compared to women, a significantly higher proportion of men report relying on their spouses, as opposed to children and friends, for all six kinds of support. On the other hand, women consistently report receiving more support than men from children and friends. These differences are especially pronounced on "affective support" such as confiding, reassuring, and talking when upset. Men are much more likely to confide in and get reassurance from their wives, whereas roughly half of the women did not report receiving such support from their husbands. It should also be noted that these married women are more likely to rely on their children rather than on their husbands for confiding, reassurance, respect, and sick care. These findings are consistent with those of Lowenthal and Haven (1968) with regard to the sex differences in a confidant.

The same trend is observed, although to a slightly lesser degree, in the measures of providing support (Table III). Most respondents, both men and women, report providing all six kinds of support to at least one member of their network. Compared to women, men are more likely to provide their spouses with support, particularly confiding, talking when upset, and talking about health. A larger proportion of women reported providing their children rather than husbands with confiding, reassurance, respect and talk when upset.

Compared to men, women are significantly more likely to provide their friends with reassurance, talk when upset, and talk about health. These findings highlight the singularity of men's support networks and the multifaceted nature of women's support networks.

Finally, the relative influences of social support measures on well-being are examined in separate regression analyses for men and women. Individual well-being was measured by a 5-point (1-5) happiness scale. The mean scores of men and women in our sample were 3.32 and 3.34, respectively. A $t$ test failed to yield a significant sex difference in reported level of wellbeing at the $p<.05$ level. The relative influence of qualitative and quantitative measures of social support on well-being is reported in the last two columns of Table I. It should be noted that because of the high correlation between number of supports received and number of supports provided a significant multicollinearity problem emerged. This made it impossible to include both measures in the regression analyses. We chose to include only the number of supports received in the regression analyses.

The multiple regression analyses indicate that social support measures explain $18 \%$ and $23 \%$ of the variance in happiness for men and women, respectively. It also appears that qualitative support measures are better predictors of happiness than quantitative measures of support. Reciprocity is the only quantitative variable that is a significant predictor for happiness. 


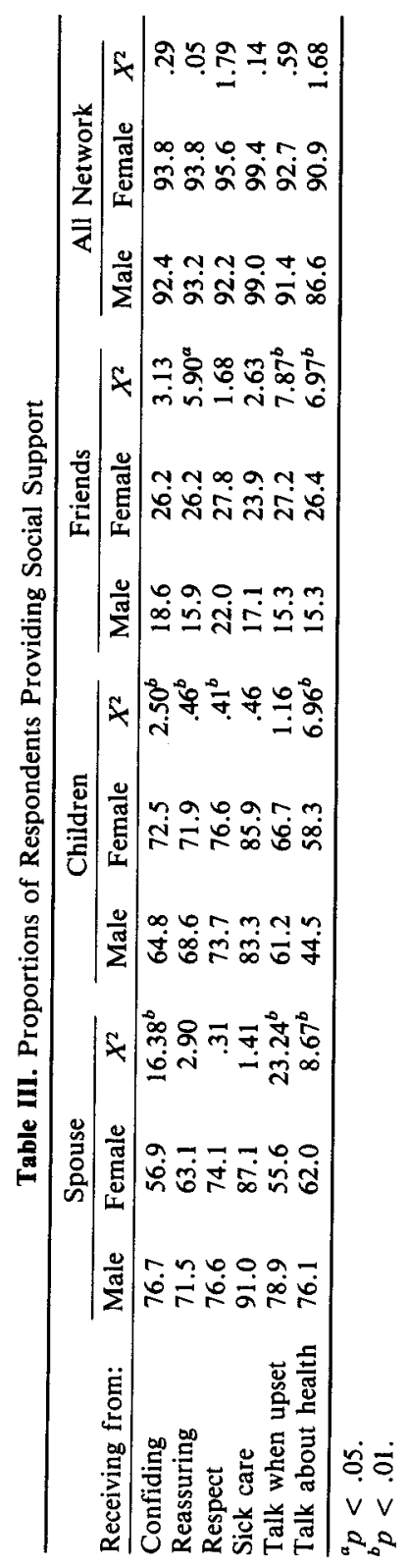


It is also the only variable that operates similarly for men and women. Since reciprocity was computed by subtracting the number of supports provided from the number of supports received, the negative regression coefficient indicates that overproviding, i.e., providing more than one receives, is positively related to happiness for both men and women. Qualitative measures of support were found to have differential effects on happiness for men and women. Men who are satisfied with their friends are more happy and men who want more people in their network are less happy. For women, these variables are not significantly related to happiness. Happy women, on the other hand, report greater satisfaction with marriage and are less likely to indicate that their network gets on their nerves.

\section{DISCUSSION}

In summary, these results suggest that the sex differences in social support are considerably more complex than one might have originally hypothesized. Our data indicate that of eight quantitative measures of social support, only two - size of network and number of supports received - are significantly different for men and women. These findings are consistent with many previous findings, and indicate that women both have larger networks and receive more supports.

The receipt and provision of six types of support indicates a clear sex difference in the role of spouse. Although most people feel they receive and provide confiding, reassurance, respect, sick care, talk when upset, and talk about health, the exchange of these supports was clearly different by sex across relationships. Men were much more likely to report receiving from and providing support to their spouses. Women were much more likely to report receiving support from and providing support to others such as children and friends. These findings are consistent with those of Lowenthal and Haven (1968) with regard to the sex differences in a confidant. Men and women seem to have different expectations, criteria, experiences, and consequently, evaluations of their intimate support relationships.

In some ways these data are intriguing because they suggest fewer sex differences than one might expect. However, a clear picture begins to emerge, which indicates that for men quantitative support differences are relatively unimportant when a wife is present. But as Levitt et al., (1985) noted, men can easily become isolated when the traditional marital role is disrupted and there is no wife present to maintain the supportive links. It is interesting that the give and take of support relationships are important for both men and women. Also interesting is that men and women prefer to be providing more than they receive. This is especially noteworthy when one recalls that this 
sample is $\mathbf{5 0}$ years of age and older, a time and age when an individual might comfortably assume that it was an appropriate time in life to receive more than provide. However, it is quite clear that, at least in this culture, it is better to give than to receive. We have speculated in other work (Antonucci \& Akiyama, 1987) that this bias allows people to maintain their own personal sense of independence. It may be that there are other structure and function support differences not tapped in the present study that serve to equalize these differences we have found. For example, women may be more likely to provide affective support whereas men are more likely to provide financial support. Thus, men and women may achieve equity between the sexes across functions rather than through direct functional reciprocity.

With the exception of reciprocity, the variables that were significantly predictive of happiness were different for men and women. It may be that these differences begin to hint at the different social experiences of men and women. For men, satisfaction with marriage is important. Since women are less likely than men to report being satisfied with their marriage, it may be that women experience a great deal more variance in satisfaction with their marital relationship. That happier women are also less likely to report that their network gets on their nerves is also suggestive. Similarly, the multifaceted nature of women's support networks may be accompanied by increased expectations. On the other hand, for men, satisfaction with friends and not wanting more people in one's network appear important for happiness. These findings are particuarly interesting in light of the fact that men seem to provide and receive most of their supportive exchanges from their wives, not their friends. Thus, it seems an extended network that is neither numerous nor intrusive is preferred, again suggesting that men do not seek the same intensity in their extended support relationships that women seek.

Review of the seven qualitative measures of support examined in this study show that men and women differ in only one measure - marital satisfaction. Contrary to what one might predict from the support literature but consistent with the marriage literature (Bernard, 1972), men report being more satisfied with their marriage than women.

Analyses designed to predict happiness using both quantitative and qualitative measures of support successfully predict $18 \%$ and $23 \%$ of the variance for men and women, respectively. Only reciprocity is a significant predictor for both regression equations. This finding indicates that both men and women are happy when they are giving more than they receive. Among the men, two additional support variables, both measures of qualitative support, are significantly related to happiness. Men who are satisfied with their friends and men who do not report wanting more people in their networks are happier. Among women, two additional variables were also significantly related to happiness, and again these were qualitative measures. Women 
satisfied with their marriages and women who do not feel their networks get on their nerves report higher levels of happiness.

That quantitative support measures account for only $9 \%$ of the variance in the qualitative measures for men, but that $20 \%$ of the variance is explained for women, is particularly interesting. The minimal relationship for men may be further evidence that variance in network structure is not critically important for men because of the important support role played by wives. For men, it appears being married, and thus having wives in their support network, is the critical quantitative or structure variable. On the other hand, several quantitative support measures contribute to a woman's assessment of her support, suggesting that the actual characteristics of her support environment do impinge upon her experience of and consequent evaluation of her supportive relationships. A further study of the most intimate relationships of men and women should provide some additionally interesting insights into the support experiences of men and women.

These data suggest that the sex difference in interpersonal relationships extends to supportive relationships. The differences between men and women in some ways are quite simple: men rely on their spouse; women rely on children and friends in addition to their spouse. The present study confirms the multifaceted nature of women's support networks, especially among married women with children. The present study also suggests that sex differences are greater in the exchange of affective support than instrumental support, at least in terms of the types of supportive measures analyzed in this study. Note that sex differences in sick care were minimal, but were considerably greater in reassurance and talking with others when upset. The implications of these differences clearly warrant further study. The role of men and women in the structure and function of support network is clearly different. Our findings suggest that major current societal changes, e.g., in women's roles and in the frequency of late life divorce, will have a differential impact on the support networks of men and women. These data suggest that the structure and function of women's network while perhaps experiencing strain is better equipped to cope with these problems. On the other hand, the support networks of men appear more fragile. Men may have more difficulty coping with the kinds of stresses most likely to be met with the current societal changes.

\section{REFERENCES}

Antonucci, T. C., \& Akiyama, H. Social networks in adult life and a preliminary examination of the convoy model. Journal of Gerontology, 1987, 42(5), 519-527.

Babchuk, N. Aging and primary relations. International Journal of Aging and Human Development, 1978-1979, 9(2), 186-204.

Bernard, J. The future of marriage. New York: World Publishing Company, 1972. 
Burda, P. C. Jr., Vaux, A., \& Schill, T. Social support resources: variation across sex and sex role. Personality and Social Psychology Bulletin, 1984, 10,(1), 119-126.

Butler, T., Giordano, S., \& Neren, S. Gender and sex-role attributes as predictors of utilization of natural support systems during personal stress events. Sex Roles, 1985, 13(9/10), 515-524.

Campbell, A. A sense of well-being in America. New York: McGraw-Hill, 1980.

Depner, C. E, \& Ingersoll-Dayton, B. Conjugal social support: Patterns in later life. Journal of Gerontology, 1985, 40(6), 761-766.

Griffith, J. Social support providers: Who are they? Where are they met? And the relationship of network characteristics to psychological distress. Basic and Applied Social Psychology, 1985, 6(1), 41-60.

Harris, L. The myth and reality of aging in America. Washington, D.C.: The National Council on Aging, 1975.

Kahn, R. L., \& Antonucci, T. C. Social supports of the elderly: Family/friends/professionals. Final report to the National Institute on Aging, No. \#AG01632, 1984.

Kessler, R. C., McLeod, J. D., \& Wethington, E. The costs of caring: A perspective on the relationships between sex and psychological distress. In I. G. Sarason \& B. R. Sarason (Eds.), Social support: Theory, research and applications. Dordrecht: Martinus Nijhoff Publishers, 1985.

Leavy, R. L. Social support and psychological disorder: A review. Journal of Community Psychology, 1983, 11, 13-19.

Levitt, M. J., Antonucci, T. C., Clark, M. C., Rotton, J., \& Finley, G. E. Social support and well-being: Preliminary indicators based on two samples of the elderly. International Journal of Aging and Human Development, 1985-86, 21(1), 61-77.

Longino, C. F., Jr., \& Lipman, A. The married, the formerly married and the never married: Support system differentials of older women in planned retirement communities. International Journal of Aging and Human Development, 1982, 15(4), 285-297.

Lowenthal, M. F., \& Haven, C. Interaction and adaptation: Intimacy as a critical variable. American Sociological Review, 1968, 33, 20-30.

Maccoby, E. E., \& Jacklin, C. N. The psychology of sex differences. Stanford, CA: Stanford University Press, 1974.

Sarason, I. G., Levine, H. M., Basham, R. B., \& Sarason, B. R. Assessing social support: The Social Support Questionnaire. Journal of Personality and Social Psychology, 1983, 44, 127-139.

Troll, L. E. Family issues in current gerontology. Gerontological Society of America: Springer Publishing Company, in press.

Vaux, A. Variations in social support associated with gender, ethnicity, and age. Journal of Social issues, 1985, 41(1), 89-110.

Veroff, J., Douvan, E., \& Kulka, R. The inner American. New York: Basic Books, 1981. 